\title{
Myocardial and cerebral infarction due to massive air embolism following endoscopic retrograde cholangiopancreatography (ERCP)
}

An 82-year-old man underwent the routine removal of a common bile duct (CBD) stent by endoscopic retrograde cholangiopancreatography (ERCP). He had been fit and well prior to the procedure, and his past medical history was unremarkable. He had presented 18 months previously with acute cholangitis caused by gallstones.

The patient was sedated, and throughout the 20-minute procedure he maintained spontaneous breathing and standard monitoring was unremarkable. After the procedure the patient was moved from a slightly left lateral position to supine. Immediately, his $\mathrm{SpO}_{2}$ dropped to $70 \%$ and he became profoundly hypotensive with a pulse of 50 beats per minute. His Glasgow Coma Scale (GCS) score was 3/15. He was given flumazenil and naloxone with no effect. An electrocardiogram showed massive anterior ST-segment elevation with reciprocal changes ( $\bullet$ Fig. $\mathbf{1}$ ). Resuscitation with high-flow oxygen $(15 \mathrm{~L} / \mathrm{min})$ and fluid restored $\mathrm{SpO}_{2}$ to $100 \%$ and blood pressure to $130 / 80 \mathrm{~mm} \mathrm{Hg}$. The patient was rushed to the cardiac catheterization laboratory where a repeat 12-lead ECG revealed complete resolution of the ST-segment elevation within 20 minutes, although the GCS score remained at 3/15. Generalized hypertonicity and a transiently dilated right pupil were noted, raising suspicion of an intracranial event. The patient was haemodynamically stable and a computed tomography (CT) scan of the head was urgently carried out. The scan revealed large quantities of air in both hemispheres of the cerebral circulation $(\bullet$ Fig. 2). The patient was subsequently transferred to the intensive care unit but did not require intubation due to an improvement in his conscious level (GCS score 8/15). The troponin level at 12 hours post event was significantly elevated at $0.85 \mathrm{ng} / \mathrm{mL}$.

Systemic air embolism following ERCP has only been described on four previous occasions [1-4], although reports on venous air embolism are more abundant [5]. The

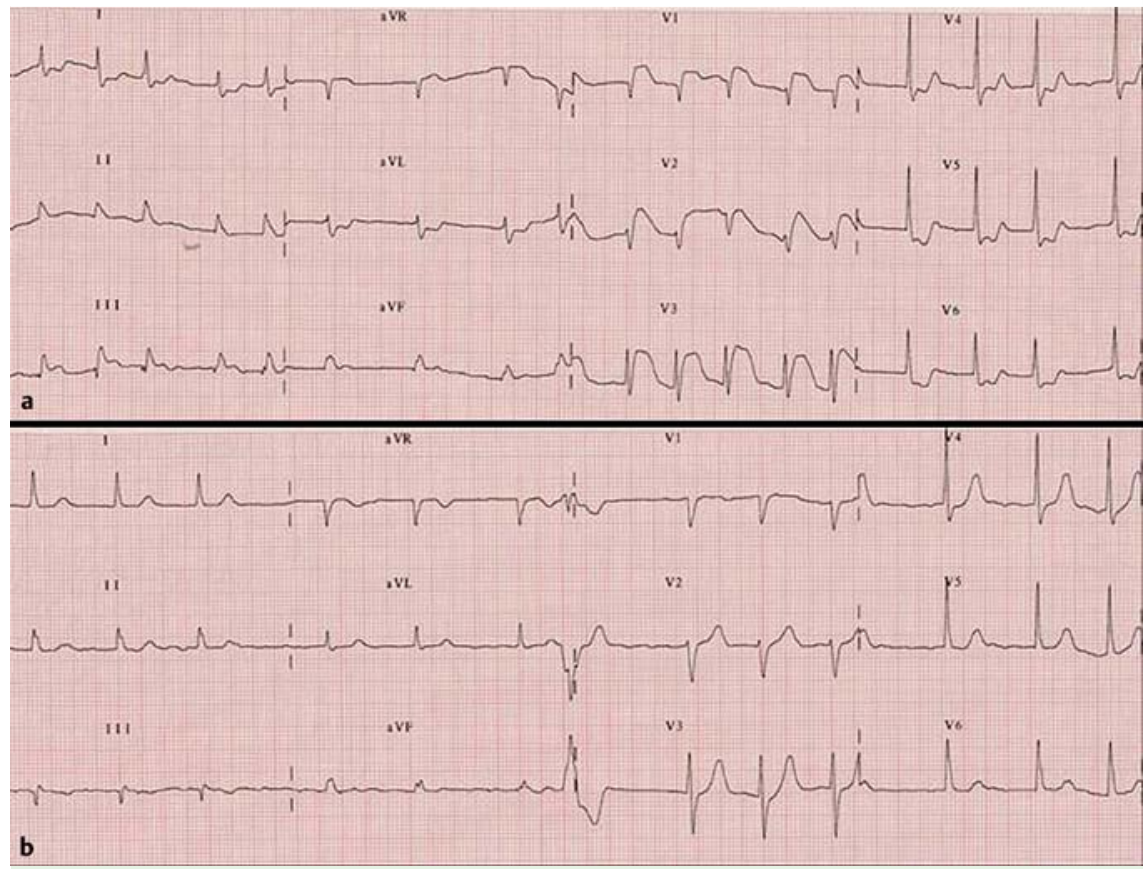

Fig. 1 12-lead electrocardiogram: a directly after endoscopic retrograde cholangiopancreatography (ERCP); and $\mathbf{b}$ at 20 minutes post ERCP.

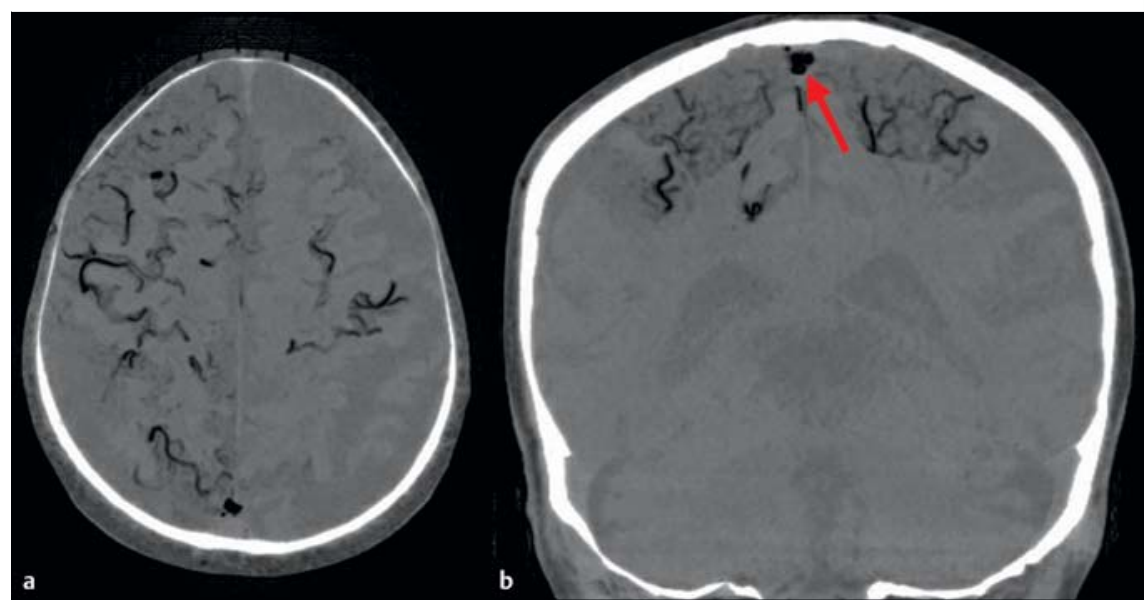

Fig. 2 Computed tomography $(\mathrm{CT})$ scan of the brain: a transverse view showing air in the cerebral veins in all the cerebral territories of the right hemisphere and the middle cerebral territory of the left hemisphere; and $\mathbf{b}$ coronal view showing air in the sagittal sinus (red arrow).

present case is novel in that myocardial infarction due to air embolism after ERCP has not previously been reported.

Endoscopy_UCTN_Code_CPL_1AK_2AC 
G. I. van Boxel ${ }^{1}$, C. E. Hommers ${ }^{1}$, I. Dash ${ }^{2}$,

A. J. Goodman' ${ }^{2}$, J. Green ${ }^{3}$, R. M. Orme ${ }^{1}$

1 Department of Critical Care, Cheltenham General Hospital, Cheltenham, UK

2 Department of Gastrointestinal Surgery, Cheltenham General Hospital, Cheltenham, UK

3 Department of Radiology, Cheltenham General Hospital, Cheltenham, UK

\section{References}

1 Romberg C. Systemic air embolism after ERCP: a case report and review of the literature (with video). Gastrointest Endosc 2009; 70: $1043-1045$

2 Siddiqui J, Jaffe PE, Aziz K et al. Fatal air and bile embolism after percutaneous liver biopsy and ERCP. Gastrointest Endosc 2005; 61: $153-157$

3 Stabile L, Cigada M, Stillittano D et al. Fatal cerebral air embolism after endoscopic retrograde cholangiopancreatography. Acta Anaesthesiol Scand 2006; 50: 648-649

4 Nayagam J, Ho KM, Liang J. Fatal systemic air embolism during endoscopic retrograde cholangio-pancreatography. Anaesth Intensive Care 2004; 32: 260-264

5 Kennedy C, Larvin M, Linsell J. Fatal hepatic air embolism following ERCP. Gastrointest Endosc 1997; 45: 187-188

\section{Bibliography}

DOI $10.1055 / \mathrm{s}-0029-1243826$

Endoscopy 2010; 42: E80 - E81

(c) Georg Thieme Verlag KG Stuttgart · New York . ISSN 0013-726X

\section{Corresponding author}

\section{R. M. Orme}

Department of Critical Care

Cheltenham General Hospital

Sandford Road

Cheltenham GL53 7AN

UK

Robert.orme@glos.nhs.uk 